University of Nebraska - Lincoln

DigitalCommons@University of Nebraska - Lincoln

Faculty Publications, Department of Child, Youth, and Family Studies

2021

\title{
Examining Differences in Achievement of Physical Activity Best Practices Between Urban and Rural Child Care Facilities by Age
}

Danae Dinkel

John P. Rech

Yage Guo

Matthew R. Bice

Emily Hulse

See next page for additional authors

Follow this and additional works at: https://digitalcommons.unl.edu/famconfacpub

Part of the Developmental Psychology Commons, Family, Life Course, and Society Commons, Other Psychology Commons, and the Other Sociology Commons

This Article is brought to you for free and open access by the Child, Youth, and Family Studies, Department of at DigitalCommons@University of Nebraska - Lincoln. It has been accepted for inclusion in Faculty Publications, Department of Child, Youth, and Family Studies by an authorized administrator of DigitalCommons@University of Nebraska - Lincoln. 
Authors

Danae Dinkel, John P. Rech, Yage Guo, Matthew R. Bice, Emily Hulse, Donnia Behrends, Christina Burger, and Dipti Dev 


\title{
Examining Differences in Achievement of Physical Activity Best Practices Between Urban and Rural Child Care Facilities by Age
}

\author{
Danae Dinkel, ${ }^{1}$ John P. Rech, ${ }^{1}$ Yage Guo, ${ }^{2}$ \\ Matthew Bice, ${ }^{3}$ Emily Hulse, ${ }^{4}$ Donnia Behrends, ${ }^{5}$ \\ Christina Burger, ${ }^{6} \&$ Dipti Dev ${ }^{2}$
}

1 School of Health \& Kinesiology, University of Nebraska at Omaha, 6001 Dodge St., Omaha, NE 68182, USA

2 Department of Child, Youth, and Family Studies, University of Nebraska at Lincoln, Lincoln, USA

3 Kinesiology and Sports Sciences Department, University of Nebraska at Kearney, Kearney, USA

4 Center for the Child \& Community, Children's Hospital and Medical Center, Lincoln, USA

5 Nebraska Extension, University of Nebraska at Lincoln, Lincoln, USA

6 Nebraska Department of Education, Lincoln, USA

Correspondence — Danae Dinkel, dmdinkel@unomaha.edu

\begin{abstract}
Go Nutrition and Physical activity Self Assessment in Child Care (NAP SACC) is an evidence based intervention developed to positively impact childhood obesity in early childhood education (ECE) facilities. One focus of Go NAP SACC is the development of physical activity best practices. However, little research has examined differences in achievement of best practices based on age of child and geographic
\end{abstract}

Published in Early Childhood Education Journal 2021

doi:10.1007/s10643-021-01169-2

Copyright (c) 2021 Danae Dinkel, John P. Rech, Yage Guo, Matthew Bice, Emily Hulse, Donnia Behrends, Christina Burger, and Dipti Dev, under exclusive license to Springer Nature. Used by permission.

Accepted 17 February 2021; published 9 March 2021. 
location. The purpose of this study was to examine differences in the achievement of physical activity best practices between urban and rural childcare facilities by agespecific recommendations (infants, toddlers, and preschoolers) and in the overall physical activity environment. Urban $(n=207)$ and rural $(n=218)$ ECE facilities completed the Go NAP SACC process. Data were analyzed using an ANCOVA. A majority of facilities reported exceeding best practices (79.5\%), however significant differences were found on 18 best practices with urban facilities outscoring their rural counterparts on 17 of these items. A comparison by age found that urban facilities reported higher achievement of best practices among infants (60\%) in comparison to toddlers (40\%) or preschoolers (30\%). Future studies should continue to explore the rural-urban context of physical activity practices across the early childhood age groups to ensure healthy physical development of children.

Keywords: Physical activity, Rural, Early childhood, Child care

\section{Introduction}

Childhood obesity is a notable public health concern impacting $13.9 \%$ of children 2-5 years of age (Hales et al. 2017). Children in early childhood ( $0-5$ years) who have excess body weight may experience a range of adverse physical, social, and emotional side effects that have the potential to continue into adolescence and adulthood (Cunningham et al. 2014; Singh et al. 2008; Singhal and Lucas, 2004). Therefore, programs and policies are needed to support the development of health related behaviors that lead to a healthy weight during early childhood.

Two health behaviors widely recognized as contributors to a healthy weight are increased time spent in physical activity and decreased time in non-interactive sedentary behaviors (e.g., watching TV (Barnett et al. 2018; Centers for Disease Control \& Prevention (CDC) 2017). Evidence suggests that not only can increased physical activity during early childhood lead to a healthy weight but it can also lead to improvements in the development of fine and gross motor skills as well as psychosocial skills which increase the likelihood of pursuing opportunities to be physically active later in life (Bower et al. 2008; Burdette and Whitaker, 2005; Shonkoff, 2000). However, engaging in too much non-interactive sedentary behavior during early childhood, may result in delaying motor skill development and other physical (e.g., fitness levels, bone strength) and psychosocial health (e.g. behavior, conduct problems) indicators (Janz et al. 2010; Poitras et al. 2017). Thus, there 
is growing evidence in support of the need to develop healthy behaviors by increasing physical activity and reducing sedentary time, beginning in as early as infancy (0-12 months; Bower et al. 2008; Hesketh and Campbell, 2010).

Unfortunately, the promotion of physical activity during early childhood is often times overlooked due to a common societal perception that the performance of physical activity at a young age is an innate and natural occurrence, thus there is little need to intervene (De Craemer et al. 2013; Hesketh et al. 2012). However, research shows that from birth children begin to learn how to effectively use their bodies in order to move and function within their environment. This early discovery period has been shown to be influential on children's growth and development (Culpepper and Killion, 2018; Henderson et al. 2015; Wilke et al. 2013). For example, Benjamin-Neelon et al. (2020) found from a large sample of infants, that more active infants had lower central adiposity. One setting that has the potential to positively influence children's physical activity behaviors is that of early childhood education (ECE) facilities (Finn et al. 2002; Larson et al. 2011; Pate et al. 2004). Currently in the United States, approximately $61 \%$ of children 5 years and younger, attend ECE facilities on an average of $33 \mathrm{~h}$ a week (Laughlin, 2013). In order to positively impact children's physical activity, it is imperative that ECE facilities adopt evidence-based policies and practices that create healthy environments to support healthy behaviors such as physical activity.

One initiative designed to support healthy environments in ECE is the Nutrition and Physical Activity Self Assessment for Child Care (Go NAP SACC). Go NAP SACC was developed to help ECE professionals improve their current practices, policies, and environments that have been recognized to impact the instilment of healthy habits during early childhood (Kenney et al. 2019; Ward, et al. 2008). Numerous studies have demonstrated the effectiveness of Go NAP SACC (Battista et al. 2014; Bonis et al. 2014; Dinkel et al, 2018). Further, Go NAP SACC was recently reported to have the best evidence for the impact on childhood obesity prevention among young children (Kenney et al. 2019). Through Go NAP SACC, ECE professionals complete a self-assessment based on ECE evidence-based physical activity best practices for specific age groups (infant, toddler, preschool), as well as overall health-related factors of the ECE environment. After completion of the 
self-assessment, ECE professionals receive training and are able to decide which specific goals they would like to focus on. Finally, ECE professionals complete a post-assessment to determine their progress on the implementation of best practices in their ECE facility. As ECE professionals can self-select which Go NAP SACC policies and best practices to work on, it is important to ensure that all ages are supported with the best resources available. However, limited research has examined how the changes regarding implementation of evidence-based physical activity policies and practices at post-intervention vary by the child's age.

Another factor potentially impacting physical activity in early childhood is geographic location. Previous research suggests that rural ECE professionals may experience barriers affecting the implementation of recommended best practices for physical activity including lack of local resources, facilities, and amenities as well as limited professional development and training opportunities (Dev et al. 2020; Findholt et al. 2013). However, urban ECE facilities may experience barriers related to lack of space (e.g., room for gardens) as well as difficulties in implementing policies due to the numerous staff involved with the implementation process (Dinkel et al. 2018; Tremblay et al. 2012). Conversely, Erinosho and colleagues (2016) found no differences in achievement of physical activity best practices between urban and rural family childcare homes. Therefore, the primary purpose of this study was to examine the differences between the geographical location (urban vs rural) of ECE facilities in the achievement of physical activity best practices for each of the early childhood age groups (infant, toddler, and preschool). The secondary purpose of this study was to examine these same differences in the overall implementation of environment and policy best practices set forth by Go NAP SACC.

\section{Methods}

\section{Sample}

This study investigated potential differences in Go NAP SACC best practices for physical activity and outdoor play and learning, between urban and rural ECE facilities by age group: infants (0-12 months), 
toddlers (13-24 months), and preschoolers ( $2-5$ years). ECE facilities included childcare centers and family childcare homes. Childcare centers usually have larger facilities, more staff, and care for more children. Family childcare homes are operated in the ECE professional's home and care for a smaller group of children (Dinkel et al. 2018).

Since 2010, a collaborative effort between various health-related entities in the state of Nebraska have worked to provide Go NAP SACC to ECE facilities across the state. Numerous organizations including the Nebraska Department of Education, Child and Adult Care Food Program (CACFP) Sponsor Organization, Nebraska Department of Health and Human Services, Nebraska Extension, Children's Hospital \& Medical Center, Catholic Health Initiative Healthcare system and local nonprofit organizations, have partnered to expand the program and provide trainings to ensure both urban and rural facilities across the state receive access to the Go NAP SACC training. Currently, over one thousand ECE facilities have received training from the almost 30 Nebraska Go NAP SACC trainers.

The data from the Go NAP SACC assessments are uploaded in to an online database. For the present study, ECE facilities in the state of Nebraska that participated in Go NAP SACC between August 2014 to August 2018 and completed both the pre- and post-assessments met the inclusion criteria for this study. A total of 487 ECE professionals began an assessment in the online database, however only 425 of these completed the assessment in its entirety, thus were used for analysis. Of those who completed, approximately 15,483 children from three different early childhood age groups received care from these ECE facilities (Table 1). Of the total number of young children, $26.21 \%$ were infants, $33.91 \%$ were toddlers, and $39.88 \%$ were preschool children. Any child 6 years and older in attendance at the participating ECE facilities were excluded from the sample.

ECE facilities resided in both urban and rural areas. Overall, $48.71 \%$ of ECE facilities were located in urban areas ( $n=207)$, and $51.29 \%$ of ECE facilities were located in rural areas $(n=218)$. For the purpose of this study, urban status was defined as any area with a population of 50,000 or more residents ( $n=2$ counties) and an additional seven of which were metropolitan "outlying" counties $(n=7)$ (Lin and Qu 2016). Micropolitan status was defined as an area with a population of 10,000 or more residents $(n=10)$. Rural status consisted of any 
Table 1 Characteristics of childcare facilities

\begin{tabular}{lrrr} 
& $n$ & Total N & (\%) \\
\hline No. of Providers who Completed & 425 & 487 & $87.27 \%$ \\
Total No. of Children & & 15,483 & \\
$\quad 0-12$ months & 4058 & & $26.21 \%$ \\
13-24 months & 5250 & & $33.91 \%$ \\
2-5 years & 6175 & & $39.88 \%$ \\
CACFP Participation & 386 & 425 & $90.82 \%$ \\
Residence/Location & & 425 & \\
$\quad$ Urban Classification & 207 & & $48.71 \%$ \\
$\quad$ Rural Classification & 218 & & $51.29 \%$ \\
\hline
\end{tabular}

population smaller than micropolitan $(n=74)$. For the purpose of the analysis and consistent with other literature, micropolitan and rural counties were combined to be able to compare differences across urban (metropolitan) and rural (micropolitan and rural) (Frampton et al. 2014; Natale et al. 2014).

\section{Measures}

Nebraska utilizes five instruments from the Go NAP SACC self-assessment at pre- and post-intervention which measure Child Nutrition, Breastfeeding and Infant Feeding, Infant and Child Physical Activity, Outdoor Play and Learning, and Screen Time (Ward et al. 2014). All items on the self-assessments are based on evidence-based best practices for ECE standards and are answered on a four-point Likert scale (Ammerman et al. 2007; Trost et al. 2011). Answers varied based on the item and were coded as $1=$ marginally meeting childcare standards, 2 = meeting childcare standards, 3 = exceeding childcare standards, and $4=$ far exceeding childcare standards and meeting the Go NAP SACC recommended best practices (Trost et al. 2011). Assessments were completed by the ECE facility director or owner. The assessment was hosted through a secured online server (University of NebraskaLincoln, n.d.). For this particular study, only the Infant and Child Physical Activity and Outdoor Play and Learning constructs of the Go NAP SACC assessment were utilized. Items from these two constructs were 
divided according to age specific practices resulting in five items for infants, five items for toddlers, and nine items for preschool children. The remaining non-age specific items from the two constructs were then grouped into a separate 'All Children' category to further assess differences in the physical activity environment between urban and rural ECE facilities.

\section{Statistical Analysis}

Descriptive statistics were calculated using the results from the Go NAP SACC post intervention self-assessments for the two physical activity related constructs (Infant and Child Physical Activity and Outdoor Play and Learning). Data from family ECE homes and ECE centers were combined to make our model more statistically powered to analyze the difference in best practices between urban and rural ECE facilities. Approximately ninety-one percent $(n=386)$ of the 425 ECE professionals reported CACFP participation. Due to the likelihood of higher rates of best practices among ECE professionals that participate in CACFP and increased likelihood of access to trainings and material related to physical activity, participation in CACFP was defined as a categorical control variable in the analysis (U.S. Department of Agriculture Food and Nutrition Service 2013, Foster et al. 2015, Welch et al. 2019). Additionally, a pretest-posttest control group design was analyzed with the posttest score as the dependent variable and the pretest score as a covariate for the analysis of covariance (ANCOVA).

ANCOVA was used to determine whether there were any statistically significant differences between the adjusted means of physical activity best practices at ECE facilities in rural locations compared to urban locations, having controlled for CACFP participation and pretest assessment score as covariates. The Sidak-Bonferroni correction was applied to adjust the multiple comparisons. The $P$-value for the physical activity items was Sidak-Bonferroni $=1-(1-0.05)^{\wedge} 0.05=$ 0.003 , and the $P$-value for outdoor play items was Sidak-Bonferroni $=$ $1-(1-0.05)^{\wedge} 0.067=0.003$. 
Table 2 Statistical effects for physical activity and outdoor play for infant age group

\begin{tabular}{|c|c|c|c|c|c|}
\hline Items & $d f, d f$ error & $F$ & $P$ & Location & Means \\
\hline \multirow[t]{2}{*}{ Time provided: Offering tummy time to non-crawling infants } & 1,421 & 3.68 & 0.341 & Urban & 3.21 \\
\hline & & & & Rural & 3.09 \\
\hline \multirow{2}{*}{$\begin{array}{l}\text { Time provided: Amount of time infants spend in seats, swings, } \\
\text { or ExcerSaucers }\end{array}$} & 1,421 & 6.15 & 0.0019 & Urban & 3.58 \\
\hline & & & & Rural & 2.92 \\
\hline \multirow{2}{*}{$\begin{array}{l}\text { Indoor play environment: Offering developmentally appropriate } \\
\text { portable play equipment to infants }\end{array}$} & 1,421 & 4.06 & 0.632 & Urban & 3.60 \\
\hline & & & & Rural & 3.52 \\
\hline \multirow{2}{*}{$\begin{array}{l}\text { Daily practices: During tummy time and other activities, interacting } \\
\text { with infants to help build motor skills }\end{array}$} & 1,421 & 8.32 & 0.001 & Urban & 3.64 \\
\hline & & & & Rural & 3.12 \\
\hline \multirow[t]{2}{*}{ Outdoor play time: Amount of time infants are taken outdoors } & 1,421 & 5.47 & 0.0015 & Urban & 3.37 \\
\hline & & & & Rural & 2.63 \\
\hline
\end{tabular}

Significant difference $(P<0.003)$; Sidak-Bonferroni correction was applied.

\section{Results}

Overall, after completing the Go NAP SACC process, on average ECE facilities were at least meeting childcare standards for all physical activity and outdoor play and learning best practices within the self-assessment. Further, for a majority (79.5\%) of best practices, facilities reported they were exceeding childcare standards.

\section{Comparison of ECE Settings for Infants}

Among the infant age group, when comparing urban and rural ECE facilities, significant differences were found for three of the five items related to physical activity and outdoor play and learning environment (Table 2). Urban ECE professionals reported higher levels of amount of time infants spend in seats, swings, or ExcerSaucers $(F(1$, $421)=3.68, p=0.0019)$; interacting with infants to help build motor skills during tummy time and other activities $(F(1,421)=8.32$, $p$ $=0.001)$; and amount of time infants are taken outdoors $(F(1,421)=$ 5.47, $\mathrm{p}=0.0015$ ).

\section{Comparison of ECE Settings for Toddlers}

Significant differences were found for two of the five items in regard to physical activity and outdoor play for the toddler age group (Table 3). Urban ECE professionals reported higher levels of offering portable 
Table 3 Statistical effects for physical activity and outdoor play for toddler age group

\begin{tabular}{|c|c|c|c|c|c|}
\hline Items & $d f, d f$ error & $F$ & $P$ & Location & Means \\
\hline \multirow{2}{*}{$\begin{array}{l}\text { Time provided: Amount of time provided to toddlers for indoor } \\
\text { and outdoor physical activity }\end{array}$} & \multirow[t]{2}{*}{1,421} & \multirow[t]{2}{*}{5.25} & \multirow[t]{2}{*}{0.611} & Urban & 3.46 \\
\hline & & & & Rural & 3.35 \\
\hline \multirow{2}{*}{$\begin{array}{l}\text { Indoor play environment: Offering portable play equipment to } \\
\text { toddlers during indoor free play time }\end{array}$} & \multirow[t]{2}{*}{1,421} & \multirow[t]{2}{*}{7.09} & \multirow[t]{2}{*}{0.0021} & Urban & 3.65 \\
\hline & & & & Rural & 3.14 \\
\hline \multirow{2}{*}{$\begin{array}{l}\text { Daily practices: Removal of children from active play time for } \\
\text { longer than } 5 \mathrm{~min}\end{array}$} & \multirow[t]{2}{*}{1,421} & \multirow[t]{2}{*}{3.15} & \multirow[t]{2}{*}{0.443} & Urban & 3.47 \\
\hline & & & & Rural & 3.42 \\
\hline \multirow[t]{2}{*}{ Outdoor play time: Providing outdoor play time to toddlers } & \multirow[t]{2}{*}{1,421} & \multirow[t]{2}{*}{9.26} & \multirow[t]{2}{*}{0.0015} & Urban & 3.31 \\
\hline & & & & Rural & 2.75 \\
\hline \multirow[t]{2}{*}{ Outdoor play time: Amount of outdoor play time provided to toddlers } & \multirow[t]{2}{*}{1,421} & \multirow[t]{2}{*}{5.64} & \multirow[t]{2}{*}{0.662} & Urban & 3.24 \\
\hline & & & & Rural & 3.12 \\
\hline
\end{tabular}

Significant difference $(P<0.003)$; Sidak-Bonferroni correction was applied.

play equipment to toddlers during indoor free play time $(F(1,421)=$ $5.25, p=0.0021)$ and providing outdoor play time to toddlers $(F(1$, 421) $=9.26, p=0.0015$ ).

\section{Comparison of ECE Settings for Preschool Children}

When examining urban and rural ECE facilities for children of preschool age, significance differences were found for three of the ten physical activity and outdoor play items (Table 4). Urban ECE professionals reported higher levels of amount of daily adult-led physical activity provided $(F(1,421)=11.07, p=0.0010)$; supervising, verbally encouraging, and participating in preschool children's physical activity $(F(1,421)=8.25), p=0.0016)$; and providing outdoor play time to preschool children $(F(1,421)=9.48, p=0.0015)$.

\section{Comparison of ECE Settings for All Children}

When examining differences among all age groups, significant differences were found in $40 \%$ of the physical activity and outdoor play items ( 10 out of 25 items; Table 5). Out of the 10 items to have found to be significantly different, urban ECE professionals reported higher levels for nine of those items when compared to their rural counterparts. These nine items included availability of indoor portable play equipment in good condition for children to use $(F(1,421)=10.28$, $\mathrm{p}=0.0017)$; incorporating physical activity into classroom routines, 
Table 4 Statistical effects for physical activity and outdoor play for preschool children age group

\begin{tabular}{|c|c|c|c|c|c|}
\hline Items & $d f, d f$ error & $F$ & $P$ & Location & Means \\
\hline \multirow{2}{*}{$\begin{array}{l}\text { Time provided: Amount of time provided to preschool children } \\
\text { for indoor and outdoor physical activity }\end{array}$} & \multirow[t]{2}{*}{1,421} & \multirow[t]{2}{*}{4.46} & \multirow[t]{2}{*}{0.673} & Urban & 3.32 \\
\hline & & & & Rural & 3.24 \\
\hline \multirow{2}{*}{$\begin{array}{l}\text { Time provided: Amount of time preschool children and toddlers } \\
\text { are expected to remain seated at any one time }\end{array}$} & \multirow[t]{2}{*}{1,421} & \multirow[t]{2}{*}{4.61} & \multirow[t]{2}{*}{0.732} & Urban & 3.38 \\
\hline & & & & Rural & 3.27 \\
\hline \multirow[t]{2}{*}{ Time provided: Amount of daily adult-led physical activity provided } & \multirow[t]{2}{*}{1,421} & \multirow[t]{2}{*}{11.07} & \multirow[t]{2}{*}{0.0010} & Urban & 3.56 \\
\hline & & & & Rural & 3.03 \\
\hline \multirow{2}{*}{$\begin{array}{l}\text { Indoor play environment: Offering portable play equipment to } \\
\text { preschool children during indoor free play time }\end{array}$} & \multirow[t]{2}{*}{1,421} & \multirow[t]{2}{*}{6.83} & \multirow[t]{2}{*}{0.721} & Urban & 3.44 \\
\hline & & & & Rural & 3.26 \\
\hline \multirow{2}{*}{$\begin{array}{l}\text { Daily practices: Removal of children from active play time } \\
\text { for longer than } 5 \mathrm{~min}\end{array}$} & \multirow[t]{2}{*}{1,421} & \multirow[t]{2}{*}{6.17} & \multirow[t]{2}{*}{0.243} & Urban & 3.52 \\
\hline & & & & Rural & 3.45 \\
\hline \multirow{2}{*}{$\begin{array}{l}\text { Daily practices: Supervising, verbally encouraging, and participating } \\
\text { in preschool children's physical activity }\end{array}$} & \multirow[t]{2}{*}{1,421} & \multirow[t]{2}{*}{8.25} & \multirow[t]{2}{*}{0.0016} & Urban & 3.57 \\
\hline & & & & Rural & 3.12 \\
\hline \multirow{2}{*}{$\begin{array}{l}\text { Education and professional development: Preschool children and } \\
\text { toddlers participate in planned lessons focused on building } \\
\text { gross motor skills }\end{array}$} & \multirow[t]{2}{*}{1,421} & \multirow[t]{2}{*}{4.18} & \multirow[t]{2}{*}{0.512} & Urban & 3.46 \\
\hline & & & & Rural & 3.38 \\
\hline \multirow[t]{2}{*}{ Outdoor play time: Providing outdoor play time to preschool children } & \multirow[t]{2}{*}{1,421} & \multirow[t]{2}{*}{9.48} & \multirow[t]{2}{*}{0.0015} & Urban & 3.34 \\
\hline & & & & Rural & 2.71 \\
\hline \multirow{2}{*}{$\begin{array}{l}\text { Outdoor play time: Amount of outdoor play time provided to } \\
\text { preschool children }\end{array}$} & \multirow[t]{2}{*}{1,421} & \multirow[t]{2}{*}{4.51} & \multirow[t]{2}{*}{0.834} & Urban & 3.28 \\
\hline & & & & Rural & 3.15 \\
\hline Outdoor play environment: Offering a variety of outdoor play & 1,421 & 3.89 & 0.642 & Urban & 3.37 \\
\hline spaces for preschool children & & & & Rural & 3.31 \\
\hline
\end{tabular}

Significant difference $(P<0.003)$; Sidak-Bonferroni correction was applied.

transitions, and planned activities $(F(1,421)=11.35, p=0.0012)$; talking with children informally about the importance of physical activity $(F(1,421)=7.69, p=0.0020)$; completing professional development on children's physical activity $(F(1,421)=5.73, p=0.0025)$; offering families information on children's physical activity $(F(1,421)$ $=6.47, \mathrm{p}=0.0022)$; the open area used for outdoor games and group activities is large enough for all children $(F(1,421)=11.43$, $\mathrm{p}=0.0015)$; providing a variety of portable play equipment and in good condition for children for use outdoors $(F(1,421)=12.04, p$ $=0.0010)$; the amount of portable play equipment available to children during outdoor active play time $(F(1,421)=9.23, p=0.0018)$; and offering families information on outdoor play and learning ( $F(1$, $421)=7.64, p=0.0022$ ). Rural ECE professionals reported significantly higher levels of the garden in the outdoor play space that grows fruits and/or vegetables for children's meals and snacks ( $F(1$, 421) $=3.72, p=0.0011)$. 
Table 5 Statistical effects for physical activity and outdoor play for all children

\begin{tabular}{|c|c|c|c|c|c|}
\hline Items & $d f, d f$ error & $F$ & $P$ & Location & Means \\
\hline \multirow{2}{*}{$\begin{array}{l}\text { Indoor play environment: Offering a variety of indoor feature } \\
\text { play spaces for children }\end{array}$} & \multirow[t]{2}{*}{1,421} & \multirow[t]{2}{*}{4.48} & \multirow[t]{2}{*}{0.733} & Urban & 3.24 \\
\hline & & & & Rural & 3.18 \\
\hline \multirow{2}{*}{$\begin{array}{l}\text { Indoor play environment: Availability of indoor portable play } \\
\text { equipment in good condition for children to use }\end{array}$} & \multirow[t]{2}{*}{1,421} & \multirow[t]{2}{*}{10.28} & \multirow{2}{*}{0.0017} & Urban & 3.57 \\
\hline & & & & Rural & 3.08 \\
\hline \multirow{2}{*}{$\begin{array}{l}\text { Indoor play environment: Availability/variety of a collection of posters, } \\
\text { books, and other learning materials that promote physical activity }\end{array}$} & \multirow[t]{2}{*}{1,421} & \multirow[t]{2}{*}{3.53} & \multirow[t]{2}{*}{0.854} & Urban & 3.21 \\
\hline & & & & Rural & 3.14 \\
\hline \multirow{2}{*}{$\begin{array}{l}\text { Education and professional development: Incorporating physical } \\
\text { activity into classroom routines, transitions, and planned activities }\end{array}$} & \multirow[t]{2}{*}{1,421} & \multirow[t]{2}{*}{11.35} & \multirow[t]{2}{*}{0.0012} & Urban & 3.48 \\
\hline & & & & Rural & 2.91 \\
\hline \multirow{2}{*}{$\begin{array}{l}\text { Talking with children informally about the importance of } \\
\text { physical activity }\end{array}$} & \multirow[t]{2}{*}{1,421} & \multirow[t]{2}{*}{7.69} & \multirow[t]{2}{*}{0.0020} & Urban & 3.42 \\
\hline & & & & Rural & 2.89 \\
\hline \multirow[t]{2}{*}{ Completing professional development on children's physical activity } & 1,421 & 5.73 & 0.0025 & Urban & 3.14 \\
\hline & & & & Rural & 2.72 \\
\hline Covering a variety of topics as part of this professional development & 1,421 & 3.26 & 0.645 & Urban & 2.92 \\
\hline & & & & Rural & 2.78 \\
\hline Offering families information on children's physical activity & 1,421 & 6.47 & 0.0022 & Urban & 3.26 \\
\hline & & & & Rural & 2.81 \\
\hline Offering families a variety of information on children's physical activity & 1,421 & 4.89 & 0.536 & Urban & 3.12 \\
\hline & & & & Rural & 2.95 \\
\hline Policy: Having a written policy on physical activity including a variety & 1,421 & 5.17 & 0.363 & Urban & 3.14 \\
\hline of topics & & & & Rural & 3.05 \\
\hline Outdoor play time: Providing a variety of activity types with & 1,421 & 6.08 & 0.625 & Urban & 3.53 \\
\hline children outdoors & & & & Rural & 3.38 \\
\hline Outdoor play environment: Providing ample shade in the outdoor & 1,421 & 5.65 & 0.492 & Urban & 3.45 \\
\hline play space & & & & Rural & 3.37 \\
\hline The open area used for outdoor games and group activities is large & 1,421 & 11.43 & 0.0015 & Urban & 3.58 \\
\hline enough for all children & & & & Rural & 3.12 \\
\hline The garden in the outdoor play space grows fruits and/or vegetables & 1,421 & 3.72 & 0.0011 & Urban & 2.82 \\
\hline for children's meals and snacks & & & & Rural & 3.26 \\
\hline The path for wheeled toys is paved and 5 feet wide & 1,421 & 4.06 & 0.874 & Urban & 3.18 \\
\hline & & & & Rural & 3.16 \\
\hline The shape of the path for wheeled toys is curved and looped & 1,421 & 5.24 & 0.795 & Urban & 3.23 \\
\hline & & & & Rural & 3.19 \\
\hline Providing path with multiple types of connections for wheeled toys & 1,421 & 4.13 & 0.742 & Urban & 3.12 \\
\hline connects to different parts of the outdoor play space & & & & Rural & 3.08 \\
\hline Providing a variety of portable play equipment and in good & 1,421 & 12.04 & 0.0010 & Urban & 3.67 \\
\hline condition for children to use outdoors & & & & Rural & 3.21 \\
\hline Portable play equipment is available to children during outdoor & 1,421 & 6.91 & 0.854 & Urban & 3.57 \\
\hline active play time & & & & Rural & 3.52 \\
\hline The amount of portable play equipment available to children & 1,421 & 9.23 & 0.0018 & Urban & 3.55 \\
\hline during outdoor active play time & & & & Rural & 3.12 \\
\hline Education and professional development: Completing professional & 1,421 & 4.82 & 0.435 & Urban & 3.14 \\
\hline development on outdoor play and learning & & & & Rural & 3.09 \\
\hline Covering a variety of topics as part of this professional development & 1,421 & 4.65 & 0.583 & Urban & 3.11 \\
\hline & & & & Rural & 3.05 \\
\hline Offering families information on outdoor play and learning & 1,421 & 7.64 & 0.0022 & Urban & 3.25 \\
\hline & & & & Rural & 2.82 \\
\hline Offering families a variety of information on outdoor play and & 1,421 & 5.36 & 0.446 & Urban & 3.16 \\
\hline learning & & & & Rural & 3.07 \\
\hline Policy: Having a written policy on outdoor play and learning & 1,421 & 4.18 & 0.733 & Urban & 3.10 \\
\hline including a variety of topics & & & & Rural & 3.03 \\
\hline
\end{tabular}




\section{Discussion}

The purpose of this study was to examine the differences between the geographical location (urban vs. rural) of ECE facilities in the achievement of physical activity best practices for each early childhood age group (infant, toddler, and preschool) as well as the overall implementation of environment and policy best practices set forth by Go NAP SACC. Importantly, for a majority of the physical activity and outdoor play and learning best practices, ECE facilities were exceeding childcare standards. When comparing post-intervention assessment scores for the physical activity best practices of urban and rural ECE facilities, both similarities and differences were found. Interestingly, of the 45 items, significant differences were found for 18 of the items. However, of the 18 items found to be significantly different, urban ECE facilities scored significantly higher than their rural counterparts on 17 of those items supporting the literature illustrating barriers present in rural settings (Dev et al. 2020; Findholt et al. 2013). Future research is needed to explore the reasons for such findings.

A comparison of differences based on the achievement of physical activity and outdoor play and learning best practices by age group found that urban facilities reported higher achievement of best practices among infants $(60 \%)$ in comparison to toddlers $(40 \%)$ or preschoolers (30\%). This is important to note especially considering research reporting higher prevalence of obesity among children residing in rural locations compared to their urban counterparts (Johnson \& Johnson, 2015; Ogden et al. 2018). While the percentages were reduced as children age, infancy is increasingly recognized as a critical time in the development and establishment of physical activity behaviors (Gillman, 2010; Gunner et al. 2005). Unfortunately, often times adults believe infants are "active enough" and not in need of opportunities for physical activity. Go NAP SACC does not currently provide a recommendation for a specific number of minutes in a day infants should be active. The World Health Organization (WHO) recently released guidelines on physical activity, sedentary behavior, and sleep for children under 5 years of age. They suggest that infants should be active several times a day with at least 30 min of tummy time and should not be restrained for more than one hour at a time (World 
Health Organization, 2019). A study conducted in Australia found that a low percentage of infants were achieving these guidelines with only $29.7 \%$ obtaining the tummy time recommendations and $56.9 \%$ meeting the restraint recommendation (Hesketh et al. 2017). Further, a study of childcare professionals found that many providers thought that infants should be active for 45 min or less every day (Hesketh et al. 2015). Regardless, improving quality and duration of tummy time can serve as an important health promotion strategy that can have a significant impact on motor development (Johnson, 2003; Wen et al. 2011). Importantly, infants should be provided additional opportunities and environments to facilitate movement outside of tummy time such as crawling mats, push and pull toys, reaching for and grasping toys (as mentioned in the Go NAP SACC best practices) to further improve developmental outcomes (Tremblay et al. 2017). Continued efforts especially in rural communities should focus on awareness of the importance of promoting best practices for infant physical activity and outdoor play.

One potential explanation for the overwhelming favor of urban facilities within the 18 differences that were found is the access to ECE professional development opportunities that focus on early childhood health behaviors and practices. Professional development and training provides ECE professionals with ideas, strategies, and additional resources that show how to improve the quality of care by promoting physical activity through vocal encouragement, improving the indoor and outdoor environment, and incorporating physical activity into planned daily routines (Egert et al. 2018; Weaver et al. 2014). Additionally, professional development facilitates the open networking between ECE professionals. This is of heightened importance as ECE professionals have reported their colleagues are a commonly used resource for new ideas, activities, and best practices to promote physical activity (van Zandvoort et al. 2010). However, Buckler and Bredin (2018), reported that ECE professionals identified a need for more professional development on physical activity best practices in order to increase their confidence in facilitating physical activity within the ECE setting.

Results from our study show urban ECE professionals scored significantly higher on completing professional development on children's physical activity, which is in agreeance with findings from other research (Hallam et al. 2017). ECE professionals who reside in urban 
settings may have an increased availability of professional trainings, in addition to being of closer proximity to these opportunities (Dev et al. 2020; Fiene, 1998; Maher et al. 2008). Thus, it may be more challenging for rural ECE professionals to access the necessary professional development due to a decreased prevalence of available services, increased travel time and increased costs to attend these opportunities (Dev et al. 2020; Malik et al. 2018; Walker, 2002). It is also important to recognize that in the state of Nebraska a majority of rural ECE facilities are family childcare homes. This further limits their availability to attend professional development during the work week due to them being the sole professional within the ECE facility.

Given ECE professionals have reported a high level of access to a number of devices at either work or home with access to the Internet, rural ECE professionals may greatly benefit from having access to online or hybrid professional development opportunities (Kyzar et al. 2014; Stone-MacDonald \& Douglass, 2015; Weigel et al. 2012). Online opportunities allow ECE professionals flexibility in completing state requirements for professional development within their homes or place of work without the burden of travel costs and time (StoneMacDonald \& Douglass, 2015; Weigel et al. 2012). In addition, online trainings - including physical activity trainings-have shown to be as effective in improving quality of care for children as in-person trainings (Powell et al. 2010; Saunders et al. 2019; Stone-MacDonald \& Douglass, 2015). Hybrid formats combine the strengths of face-toface interaction and distant features offered by online accessibility. Hybrid opportunities would allow urban and rural ECE professionals to cross pollinate practices. However, there is a need to further develop and enhance online and hybrid models for ECE professional development, such as making the models and their supplemental resources easily accessible and more personable (Stone-MacDonald \& Douglass, 2015). Additionally, there is a need to ensure all rural entities have appropriate access to broadband WiFi.

Another potential explanation for the differences observed for ECE physical activity best practices between urban and rural ECE facilities is the lack of equity for funding to supply physical activity resources, materials, and equipment (Foster et al. 2015). While food and nutrition programs benefit from professional development and policies required due to adherence to nutrition standards through the Child 
and Adult Care Food Program (CACF) - a federal policy such as this does not currently exist for physical activity (Welch et al. 2019). Further, facilities who participate and receive reimbursement through CACFP are more likely to achieve best practices for nutrition in comparison to facilities who do not participate in the program (Liu et al. 2016). CACFP is the number one sought funding source among ECE professionals in Nebraska (Welch et al. 2019). The potential inclusion of physical activity policies within entities that provide reimbursement such as CACFP and/or other state (e.g., quality rating improvement systems) or federal entities could improve achievement of best practices. Importantly, while research does support the need for equitable funding, additional research is needed to examine the existence and implications of equity of available funding on state-wide levels between urban and rural ECE facilities (Foster et al. 2015; Hallam et al. 2017; Walker, 2002).

In this study, rural ECE professionals reported providing significantly lower outdoor play time across all three early childhood age groups compared to urban ECE professionals. This is an area of concern as opportunities for children to be outside have been found to be a predictor of levels of physical activity during childhood (Burdette \& Whitaker, 2005; Hinkley et al. 2008; Pate et al. 2008; Vanderloo et al. 2013). However, when specifically examining if weather impacted the amount of time spent in outdoor play during childcare conflicting results have been found due to the variability of seasonal weather patterns in different geographic regions and policies concerning weather (Carson et al. 2010; Carson \& Spence, 2010; Copeland et al. 2011; Finn et al. 2002; Fisher et al. 2005; van Zandvoort et al. 2010). Therefore, based on results of this study it is speculated that there may be potential differences in weather policies and preferences pertaining specifically to outdoor play between urban and rural ECE facilities that may influence whether children are provided outdoor time. However, having a weather policy for outdoor play is not specifically mentioned by the Go NAP SACC assessment, therefore it was not accounted for in this study. More research is needed to specifically examine weather policy differences by comparing urban and rural settings in different regions (e.g., South vs. Midwest), and how this might impact outdoor play time.

There are several limitations to this study. First, the Go NAP SACC tool is a self-reported assessment and thus may not represent actual 
physical activity practices within the ECE facility. Further, there were no objective assessments of physical activity to ensure these practices were being translated into improved outcomes for children. Also, there are fewer number of items assessing infant physical activity than toddler and preschooler physical activity in the Go NAP SACC assessment. Furthermore, professional development opportunities are broadly defined within the Go NAP SACC center assessment (trainings, reading a book, etc.), and interpretation of opportunities could have impacted ECE perception of available opportunities and resources. Funding challenges exist and future research should examine the potential inequities in ECE funding mechanisms at the state and national level. Future research should also obtain objective assessments of children's physical activity in relation to self-report achievement of these best practices.

\section{Conclusion}

Although evidence from this study supports the need to consider the differences for best practices according to early childhood age groups and the urban-rural contexts, more research is needed to understand the reasons for differences in implementation of best practices between urban and rural ECE facilities across the three age groups of early childhood. Thus, there is a need to develop and identify relevant resources for continued improvement of best practices based on geographical location (Dinkel et al. 2018). In order to better support ECE professionals to adopt physical activity best practices professional development needs to be more readily accessible, equitable funding needs to be provided to offset the cost of implementing physical activity best practices and attending professional development, and policy needs to directly address the physical activity practices of the ECE facility in order to achieve early childhood physical activity recommendations.

Acknowledgments We would like to thank all of the Nebraska Go NAP SACC trainers and ECE professionals.

Funding This work was supported by the Cooperative Agreement Number 
NU58DP004819, funded by the Centers for Disease Control and Prevention. Its contents are solely the responsibility of the authors and do not necessarily represent the official views of the Centers for Disease Control and Prevention or the Department of Health and Human Services. This work was also supported by the Nebraska Department of Health and Human Services Child Care and Development Fund, USDA Nebraska Team Nutrition, and a Title V Maternal and Child Health Block Grant.

Data Availability Data is available from the lead author by request.

Conflict of interest The authors report no conflicts of interest.

\section{References}

Ammerman, A. S., Benjamin, S. E., Ward, D. S., Ball, S. C., Sommers, J. K., Molloy, M., \& Dodds, J. M. (2007). An intervention to promote healthy weight: Nutrition and Physical Activity Self- Assessment for Child Care (NAP SACC) theory and design. Preventing Chronic Disease, 4(3), A67-A67.

Barnett, T. A., Kelly, A. S., Young, D. R., Perry, C. K., Pratt, C. A., Edwards, N. M., et al. (2018). Sedentary behaviors in today's youth: approaches to the prevention and management of childhood obesity: a scientific statement from the American Heart Association. Circulation, 138(11), e142-e159.

Battista, R. A., Oakley, H., Weddell, M. S., Mudd, L. M., Greene, J. B., \& West, S. T. (2014). Improving the physical activity and nutrition environment through self-assessment (NAP SACC) in rural area child care centers in North Carolina. Preventive Medicine, 67, S10-S16.

Benjamin-Neelon, S. E., Bai, J., Østbye, T., Neelon, B., Pate, R. R., \& Crainiceanu, C. (2020). Physical activity and adiposity in a racially diverse cohort of US infants. Obesity, 28(3), 631-637.

Bonis, M., Loftin, M., Ward, D., \& Tsent, T. S. (2014). Improving physical activity in daycare interventions. Childhood Obesity, 10(4), 334-341.

Bower, J. K., Hales, D. P., Tate, D. F., Rubin, D. A., Benjamin, S. E., \& Ward, D. S. (2008). The childcare environment and children's physical activity. American Journal of Preventive Medicine, 34(1), 23-29.

Buckler, E. J., \& Bredin, S. S. (2018). Examining the knowledge base and level of confidence of early childhood educators in physical literacy and its application to practice. Early Years. https://doi.org/10.1080/09575146.2018.1514488

Burdette, H. L., \& Whitaker, R. C. (2005). Resurrecting free play in young children: looking beyond fitness and fatness to attention, affiliation, and affect. Archives of Pediatrics \& Adolescent Medicine, 159(1), 46-50.

Carson, V., \& Spence, J. C. (2010). Seasonal variation in physical activity among children and adolescents: a review. Pediatric Exercise Science, 22(1), 81-92.

Carson, V., Spence, J. C., Cutumisu, N., Boule, N., \& Edwards, J. (2010). Seasonal variation in physical activity among preschool children in a northern Canadian 
city. Research Quarterly for Exercise and Sport, 81(4), 392-399.

Centers for Disease Control \& Prevention. (2017). Healthy Young Children Thrive: Healthy practices in the early care and education (ECE) setting. https://www. cdc.gov/obesity/downloads/Early-Care-Education-ECE-WEB-508.pdf

Copeland, K. A., Sherman, S. N., Khoury, J. C., Foster, K. E., Saelens, B. E., \& Kalkwarf, H. J. (2011). Wide variability in physical activity environments and weather-related outdoor play policies in child care centers within a single county of Ohio. Archives of Pediatrics \& Adolescent Medicine, 165(5), 435-442.

Culpepper, D., \& Killion, L. (2018). Physical activity in pre-school children: role of the teacher during free play. Journal of Sports Science, 6, 144-148.

De Craemer, M., De Decker, E., De Bourdeaudhuij, I., Deforche, B., Vereecken, C., Duvinage, K., et al. (2013). Physical activity and beverage consumption in preschoolers: focus groups with parents and teachers. BMC Public Health, 13(1), 278.

Dev, D. A., Garcia, A. S., Tovar, A., Hatton-Bowers, H., Franzen-Castle, L., Rida, Z., $\&$ Behrends, D. (2020). Contextual factors influence professional development attendance among child care providers in Nebraska. Journal of Nutrition Education and Behavior, 52(3), 270-280.

Dinkel, D., Dev, D., Guo, Y., Hulse, E., Rida, Z., Sedani, A., \& Coyle, B. (2018). Improving the physical activity and outdoor play environment of family child care homes in Nebraska through go nutrition and physical activity selfassessment for child care. Journal of Physical Activity and Health, 15(10), 730-736.

Egert, F., Fukkink, R. G., \& Eckhardt, A. G. (2018). Impact of in-service professional development programs for early childhood teachers on quality ratings and child outcomes: A meta-analysis. Review of Educational Research, 88(3), 401-433.

Erinosho, T., Hales, D., Vaughn, A., Mazzucca, S., \& Ward, D. S. (2016). Impact of policies on physical activity and screen time practices in 50 child-care centers in North Carolina. Journal of Physical Activity and Health, 13(1), 59-66.

Fiene, R., et al. (1998). Child day care quality linked to opportunities for professional development: An Applied Community Psychology Example. Community Psychologist, 37(1), 10-11.

Findholt, N. E., Davis, M. M., \& Michael, Y. L. (2013). Perceived barriers, resources, and training needs of rural primary care providers relevant to the management of childhood obesity. The Journal of Rural Health, 29(s1), s17-s24.

Finn, K., Johannsen, N., \& Specker, B. (2002). Factors associated with physical activity in preschool children. The Journal of Pediatrics, 140(1), 81-85.

Fisher, A., Reilly, J. J., Montgomery, C., Kelly, L. A., Williamson, A., Jackson, D. M., \& Grant, S. (2005). Seasonality in physical activity and sedentary behavior in young children. Pediatric Exercise Science, 17(1), 31-40.

Foster, J. S., Contreras, D., Gold, A., Keim, A., Oscarson, R., Peters, P., et al. (2015). Evaluation of nutrition and physical activity policies and practices in child care 
centers within rural communities. Childhood Obesity, 11(5), 506-512.

Frampton, A. M., Sisson, S. B., Horm, D., Campbell, J. E., Lora, K., \& Ladner, J. L. (2014). What's for lunch? An analysis of lunch menus in 83 urban and rural Oklahoma child-care centers providing all-day care to preschool children. Journal of the Academy of Nutrition and Dietetics, 114(9), 1367-1374.

Gillman, M. W. (2010). Early infancy-a critical period for development of obesity a. Journal of Developmental Origins of Health and Disease, 1(5), 292-299.

Gunner, K. B., Atkinson, P. M., Nichols, J., \& Eissa, M. A. (2005). Health promotion strategies to encourage physical activity in infants, toddlers, and preschoolers. Journal of Pediatric Health Care, 19(4), 253-258.

Hales, C. M., Carroll, M. D., Fryar, C. D., \& Ogden, C. L. (2017). Prevalence of obesity among adults and youth: United States, 2015- 2016. U.S. Department of Health and Human Services, NCHS Data Brief, 288. https://www.cdc.gov/nchs/data/ databriefs/db288.pdf

Hallam, R., Hooper, A., Bargreen, K., Buell, M., \& Han, M. (2017). A two-state study of family child care engagement in Quality Rating and Improvement Systems: A mixed-methods analysis. Early Education and Development, 28(6), 669-683.

Henderson, K. E., Grode, G. M., O'Connell, M. L., \& Schwartz, M. B. (2015). Environmental factors associated with physical activity in childcare centers. International Journal of Behavioral Nutrition and Physical Activity, 12(1), 43.

Hesketh, K. D., \& Campbell, K. J. (2010). Interventions to prevent obesity in 0-5 year olds: an updated systematic review of the literature. Obesity, 18(S1), S27-S35.

Hesketh, K. D., Downing, K. L., Campbell, K., Crawford, D., Salmon, J., \& Hnatiuk, J. A. (2017). Proportion of infants meeting the Australian 24-hour Movement Guidelines for the Early Years: data from the Melbourne InFANT Program. BMC Public Health, 17(5), 191-198.

Hesketh, K. D., Hinkley, T., \& Campbell, K. J. (2012). Children's physical activity and screen time: qualitative comparison of views of parents of infants and preschool children. International Journal of Behavioral Nutrition and Physical Activity, 9(1), 152.

Hesketh, K. R., Van Sluijs, E. M., Blaine, R. E., Taveras, E. M., Gillman, M. W., \& Neelon, S. E. B. (2015). Assessing care providers' perceptions and beliefs about physical activity in infants and toddlers: baseline findings from the Baby NAP SACC study. BMC Public Health, 15(1), 100.

Hinkley, T., Crawford, D., Salmon, J., Okely, A. D., \& Hesketh, K. (2008). Preschool children and physical activity: a review of correlates. American Journal of Preventive Medicine, 34(5), 435-441.

Janz, K. F., Letuchy, E. M., Gilmore, J. M. E., Burns, T. L., Torner, J. C., Willing, M. C., \& Levy, S. M. (2010). Early physical activity provides sustained bone health benefits later in childhood. Medicine and Science in Sports and Exercise, 42(6), 1072.

Johnson, K. (2003). Reduced tummy time can slow motor development. Med Post, 
39(38), 51.

Johnson, J. A., \& Johnson, A. M. (2015). Urban-rural differences in childhood and adolescent obesity in the United States: a systematic review and meta-analysis. Childhood Obesity, 11(3), 233-241.

Kenney, E. Cradock, A., Resch, S., Giles, C., \& Gortmaker, S. (2019). The costeffectiveness for reduction obesity among young children through healthy eating, physical activity, and screen time. Durham, NC: Healthy Eating Research, Issue Brief. http://healthyeatingresearch.org

Kyzar, K. B., Chiu, C., Kemp, P., Aldersey, H. M., Turnbull, A. P., \& Lindeman, D. P. (2014). Feasibility of an online professional development program for early intervention practitioners. Infants \& Young Children, 27(2), 174-191.

Larson, N., Ward, D. S., Neelon, S. B., \& Story, M. (2011). What role can childcare settings play in obesity prevention? A review of the evidence and call for research efforts. Journal of the American Dietetic Association, 111(9), 1343-1362.

Laughlin, L. (2013). Who's minding the kids? Child care arrangements: Spring 2011. United States Census. https://www.census.gov/prod/2013pubs/p70-135. pdf

Lin, G., \& Qu, M. (2016). Smart use of state public health data for health disparity assessment. Boca Raton, FL: CRC Press Taylor Francis.

Liu, S. T., Graffagino, C. L., Leser, K. A., Trombetta, A. L., \& Pirie, P. L. (2016). Obesity prevention practices and policies in child care settings enrolled and not enrolled in the Child and Adult Care Food Program. Maternal and Child Health Journal, 20(9), 1933-1939.

Maher, E. J., Frestedt, B., \& Grace, C. (2008). Differences in child care quality in rural and non-rural areas. Journal of Research in Rural Education (Online), 23(4), 1.

Malik, R., Hamm, K., Schochet, L., Novoa, C., Workman, S., \& Jessen- Howard, S. (2018). America's child care deserts in 2018. Center for American Progress. https://www.americanprogress.org/issues/early-child hood/ reports/2018/12/06/461643/americas-child-care-deserts-2018/

Natale, R., Page, M., \& Sanders, L. (2014). Nutrition and physical activity practices in childcare centers versus family childcare homes. Early Childhood Education Journal, 42(5), 327-334.

Ogden, C. L., Fryar, C. D., Hales, C. M., Carroll, M. D., Aoki, Y., \& Freedman, D. S. (2018). Differences in obesity prevalence by demographics and urbanization in US children and adolescents, 2013-2016. Journal of the American Medical Association, 319(23), 2410-2418.

Pate, R. R., Mclver, K., Dowda, M., Brown, W. H., \& Addy, C. (2008). Directly observed physical activity levels in preschool children. Journal of School Health, 78(8), 438-444.

Pate, R. R., Pfeiffer, K. A., Trost, S. G., Ziegler, P., \& Dowda, M. (2004). Physical activity among children attending preschools. Pediatrics, 114(5), 1258-1263.

Poitras, V. J., Gray, C. E., Janssen, X., Aubert, S., Carson, V., Faulkner, G., et al. (2017). Systematic review of the relationships between sedentary behaviour and health 
indicators in the early years (0-4 years). BMC Public Health, 17(5), 868.

Powell, D. R., Diamond, K. E., Burchinal, M. R., \& Koehler, M. J. (2010). Effects of an early literacy professional development intervention on head start teachers and children. Journal of Educational Psychology, 102(2), 299.

Saunders, R. P., Schenkelberg, M. A., Moyer, C., Howie, E. K., Brown, W. H., \& Pate, R. R. (2019). The translation of an evidence-based preschool physical activity intervention from in-person to online delivery of professional development to preschool teachers. Translational Behavioral Medicine, 9(6), 1186-1196.

Shonkoff, J. P. (2000). Making friends and getting along with peers. In From Neurons to Neighborhoods: The Science of Early Childhood Development. National Academies Press (US).

Singh, A. S., Mulder, C., Twisk, J. W., Van Mechelen, W., \& Chinapaw, M. J. (2008). Tracking of childhood overweight into adulthood: a systematic review of the literature. Obesity Reviews, 9(5), 474-488.

Singhal, A., \& Lucas, A. (2004). Early origins of cardiovascular disease: is there a unifying hypothesis? The Lancet, 363(9421), 1642-1645.

Stone-MacDonald, A., \& Douglass, A. (2015). Introducing online training in an early childhood professional development system: Lessons learned in one state. Early Childhood Education Journal, 43(3), 241-248.

Tremblay, L., Boudreau-Larivière, C., \& Cimon-Lambert, K. (2012). Promoting physical activity in preschoolers: A review of the guidelines, barriers, and facilitators for implementation of policies and practices. Canadian Psychology/ Psychologie canadienne, 53(4), 280.

Tremblay, M. S., Chaput, J. P., Adamo, K. B., Aubert, S., Barnes, J. D., Choquette, L., \& Gruber, R. (2017). Canadian 24-hour movement guidelines for the early years (0-4 years): an integration of physical activity, sedentary behaviour, and sleep. BMC Public Health, 17(5), 874.

Trost, S. G., Messner, L., Fitzgerald, K., \& Roths, B. (2011). A nutrition and physical activity intervention for family child care homes. American Journal of Preventive Medicine, 41(4), 392-398.

USDA Food and Nutrition Services. (2013). Child and Adult Care Food Program (CACFP). United States Department of Agriculture. http://www.fns.usda.gov/ cacfp/why-cacfp-important

Vanderloo, L. M., Tucker, P., Johnson, A. M., \& Holmes, J. D. (2013). Physical activity among preschoolers during indoor and outdoor childcare play periods. Applied Physiology, Nutrition, and Metabolism, 38(11), 1173-1175.

van Zandvoort, M., Tucker, P., Irwin, J. D., \& Burke, S. M. (2010). Physical activity at daycare: issues, challenges and perspectives. Early years, 30(2), 175-188.

Walker, S. K. (2002). Predictors of family child care providers' intentions toward professional development. Child and Youth Care Forum, 31(4), 215-231.

Ward, D. S., Benjamin, S. E., Ammerman, A. S., Ball, S. C., Neelon, B. H., \& Bangdiwala, S. I. (2008). Nutrition and physical activity in child care: results from an environmental intervention. American Journal of Preventive Medicine, 
35(4), 352-356.

Ward, D., Morris, E., McWilliams, C., Vaughn, A., Erinosho, T., Mazzuca, S., et al (2014). Go NAP SACC: Nutrition and Physical Activity Self-Assessment for Child Care, Family Child Care Edition. Center for Health Promotion and Disease Prevention and Department of Nutrition, University of North Carolina at Chapel Hill. https://gonapsacc.org/

Weaver, R. G., Beets, M. W., Saunders, R. P., Beighle, A., \& Webster, C. (2014). A comprehensive professional development training's effect on afterschool program staff behaviors to promote healthy eating and physical activity. Journal of Public Health Management and Practice, 20(4), E6.

Weigel, D. J., Weiser, D. A., Bales, D. W., \& Moyses, K. J. (2012). Identifying online preferences and needs of early childhood professionals. Early Childhood Research \& Practice, 14(2), n2.

Welch, G.W., Svoboda, E., Garrett, A., Gallagher, K., Goldberg, M., \& Daro, A. (2019). Nebraska child care market rate survey report 2019. Buffet Early Childhood Institute at the University of Nebraska.

Wen, L. M., Baur, L. A., Simpson, J. M., Rissel, C., \& Flood, V. M. (2011). Effectiveness of an early intervention on infant feeding practices and "tummy time": a randomized controlled trial. Archives of Pediatrics \& Adolescent Medicine, 165(8), 701-707.

Wilke, S., Opdenakker, C., Kremers, S. P., \& Gubbels, J. S. (2013). Factors influencing childcare workers' promotion of physical activity in children aged 0-4 years: a qualitative study. Early Years, 33(3), 226-238.

World Health Organization. (2019). Guidelines on Physical Activity, Sedentary Behavior, and Sleep for Children under 5 years of age. https://www.who.int/ publications-detail/guidelines-on-physical-activity-sedentary-behaviour-andsleep-for-children-under-5-years-of-age 